\title{
The interference of various word parts on color naming in the Stroop test
}

\author{
MARTIN H. SINGER, JOSEPH S. LAPPIN, and L. PETE MOORE \\ Vanderbilt University, Nashville, Tennessee 37240
}

\begin{abstract}
This study compared the interfering effects of various word parts on performance of the Stroop task. In different conditions, the first, middle, and last two letters of a color word formed color patches. In other conditions, random letters were attached to these word parts. In a control condition, entire words formed the color patches. While no condition produced as much interference as the control condition, the first part of a color word interfered with color naming more than other word parts. The addition of unrelated letters had little or no effect on the interference produced by the first part of a word. The results are consistent with suggestions that word perception often involves the activation of an articulatory motor program which is initiated by the first part of the word.
\end{abstract}

Several lines of research on word processing indicate that competent readers do not encode words by a letter-by-letter process. Research by Reicher (1969) and Wheeler (1970) demonstrated that subjects recognized single letters in tachistoscopically presented words with significantly greater accuracy than when the letter was embedded in randomly generated strings of letters or when the letter appeared by itself. One might conclude that competent readers process words as single units. Another interpretation, often suggested from psycholinguistic approaches to reading (Smith, 1973) and recently supported by experimental evidence (Thompson \& Massaro, 1973), posits that a competent reader capitalizes on the redundancy of probable relations between letters in English orthography. That is, the probabilistic nature of spelling patterns, or the fact that certain letters occur together frequently, allows the competent reader to intelligently guess that a letter will occur in a given letter sequence. As an obvious example, the letter " $q$ " imposes severe restrictions on the subsequent few letters in a word. If words are considered as left-to-right sequences of letters, then the first letter imposes more constraints and thus provides more information than subsequent letters. If letters are perceived in a left-to-right sequence, then the first letter should be the most important.

Empirical support for this description of the reading process is provided by a recent study by Eriksen and Eriksen (1974). Four-letter words were

This research was supported, in part, by Public Health Service Grant MH21105. We would also like to acknowledge the assistance of the students in the Psychology of Perception class of Fall 1974 in formulating this experiment. Requests for reprints should be sent to Martin H. Singer, Department of Psychology, Vanderbilt University, Nashville, Tennessee 37240. sequentially presented in two segments such that one of the letters was delayed by an interval of 0 to $500 \mathrm{msec}$, and subjects were required to pronounce the words as rapidly as possible. It was found that delay of the first letter was detrimental to performance, while delay of any of the other letters facilitated performance. Since this facilitation was dependent on whether the first letter had a constant pronunciation that was not dependent on the subsequent letters, it was concluded that the perceptual processing was associated with the activation of a motor program for pronouncing the word.

The purpose of the present study was to test the reported importance of the first letters in processing words using several variations of the Stroop test. If the first part of a word activates the motor program for a word, then the first part of a color word should interfere with the naming of an incompatible color patch. To explore the robustness of any effects due to the reduction of uncertainty, we attached randomly selected letters to the first two letters of four color words.

\section{METHOD}

\section{Subjects \\ Twenty Vanderbilt University sophomore undergraduates voluntarily participated as experimental subjects.}

\footnotetext{
Materials

The stimuli were seven lists of 100 words or letter strings. Each list of 100 words was presented on one sheet of paper, in three columns. All of the lists were generated from four color words: brown, yellow, green, and orange. In one list, each color word appeared 25 times. In the other six lists. some variation of each of those words appeared 25 times. There were lists of only the first two letters of each word, the middle two letters, and the last two letters as well as lists with randomly selected letters occupying different positions in the word. With "Xs" representing the randomly selected letters, the seven sets of stimuli can be represented in the following way:
} 


$\begin{array}{lllll}\text { LIST 1: } & \text { ORANGE } & \text { YELLOW } & \text { BROWN } & \text { GREEN } \\ \text { LIST 2: } & \text { OR } & \text { YE } & \text { BR } & \text { GR } \\ \text { LIST 3: } & \text { AN } & \text { LL } & \text { OW } & \text { EE } \\ \text { LIST 4: } & \text { GE } & \text { OW } & \text { WN } & \text { EN } \\ \text { LIST 5: } & \text { ORANXX } & \text { YELLXX } & \text { BROXX } & \text { GREXX } \\ \text { LIST 6: } & \text { ORXXGE } & \text { YEXXOW } & \text { BRXXN } & \text { GRXXN } \\ \text { LIST 7: } & \text { XXANGE } & \text { XXLLOW } & \text { XXOWN } & \text { XXEEN }\end{array}$

In Lists 5, 6, and 7, the last, middle, and first parts of the words were alternately deleted and replaced with randomly selected letters (all letters had an equal probability of occurrence). Each time the word appeared, different letters were selected to replace the deleted part of the word.

The order of the words or the letter strings was randomized within each list. All words or letter strings were written in brown, green, orange, or yellow ink. The selection of the color in which a word or letter string would be written was made with the constraint that a word, word part, or letter string could never be in the color ink it represented. That is, the word "brown," or any variation of "brown" found in the seven lists, could not be written in brown ink.

The only other apparatus was a stopwatch used by the experimenter to measure response latency.

\section{Procedure}

Subjects were tested individually, each receiving all seven conditions of the experiment. A different order of presentation for the seven conditions was generated for each subject in an effort to eliminate practice effects.

The experimenter instructed subjects to vocally identify each color patch, ignoring the letters forming those patches. The experimenter emphasized accuracy and admonished subjects to avoid errors caused by excessive speed. The experimenter also requested that subjects correct their errors. Since corrections take time, an inaccurate performance had an effect on response latency. the dependent variable. The experimenter followed the responses of subjects and monitored the accuracy of their performance. The subject began responding when the experimenter said "go," and when the subject identified the last color patch, the experimenter recorded the time taken by the subject to complete the list.

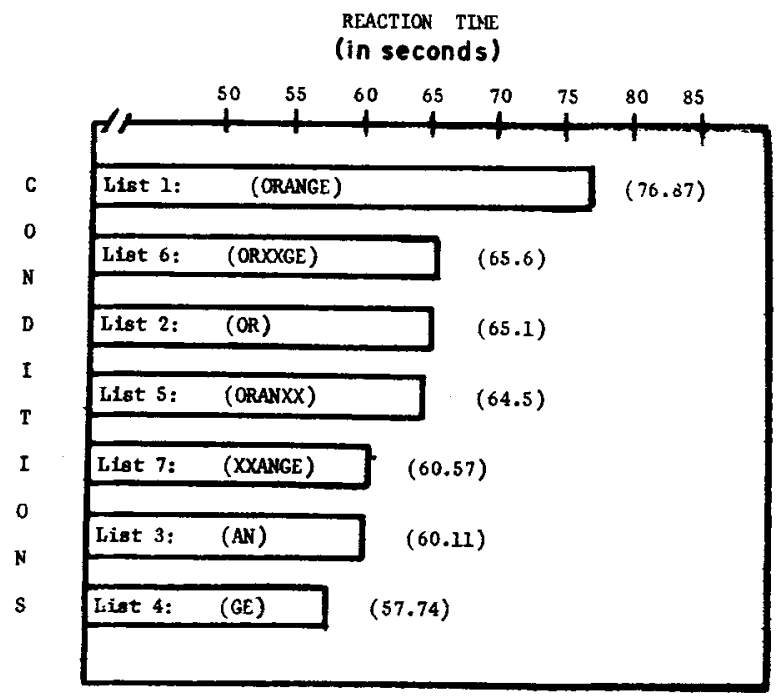

Figure 1. The average time taken to name the 100 colors in each of the experimental conditions. The word ORANGE is used as an illustration; the Xs denote randomly selected letters.

\section{RESULTS}

The data indicate that the full word interfered more than any other combination of letters. The interference of the letter strings in Lists 2, 5, and 6 was approximately equal, while each of those conditions posed more difficulty for subjects than did Conditions 3,4 , or 7 . Figure 1 summarizes these relationships.

All except one of these relationships were statistically significant by a one-tailed sign test $(n=20)$ at or above the .05 level. The analysis disclosed that the difference in interference caused by Lists 6 and 7 could have occurred by chance with a .0557 probability.

The results of the other comparisons were unambiguous. Differences between the interference caused by Lists 2,5 , and 6 were statistically nonsignificant, as were the differences between Conditions 3, 4, and 7. List 1 (entire words) caused subjects to take significantly longer in naming the color patches than any of the other lists $(\mathrm{p}<.005$ in all cases). List 2 produced more interference (the first two letters of a word) than Lists $3(p<.005), 4$ $(p<.001)$, and $7(p<.05)$. Condition 5 , in which only the last two letters of the color words were altered, also interfered with subjects' performances more than Lists $3(p<.001), 4(p<.005)$, and 7 $(p<.001)$. Condition 6 , in which the middle two letters of the color words were altered, interfered with subjects' performances more than conditions 3 $(p<.005)$ and $4(p<.001)$.

\section{DISCUSSION}

The results confirm the hypothesis that the first part of a word supplies information about the entire word, more so than other word parts. Moreover, the first part of the word supplies this information regardless of the nature of subsequent letters. That is, if the interference on the Stroop task is due to the information supplied by the letters forming the color patches, then one can reasonably argue, on the basis of this experiment, that the first part of a word supplies more information than other word parts, it does so even when other word parts are inaccurately represented or missing.

We must note, however, the apparent value (in terms of information) of all of the letters in a word. The importance of the first two letters notwithstanding, the entire word still interferes with color naming a great deal more than the first two letters presented alone or when the first two letters are followed by randomly selected letters. The results indicate that subjects do not simply guess at what a word is after seeing the first two letters. If that were 
the case, we would not expect List 1 , the list containing complete words, to interfere significantly more with color naming than List 5 , the list containing words with the last two letters randomly selected.

The results of Eriksen and Eriksen (1974) are directly relevant to the findings of the present study. They conclude that activation of the appropriate motor program for a word's pronunciation begins with knowing the first letter of a word. It would follow that the first part of a word, even when followed by random letters, should interfere with color naming.

This model is consistent with the findings of Warren (1974). In his study, words that elicited color-word associations interfered with color naming. Warren proposed that, as part of the encoding process, words trigger memory association. Thus, the process itself engenders interference in color-naming on the Stroop test. In the present study, the motor program for speech might be construed as a memory association to a word and, like any other association, its activation may interfere with the encoding of the color patch.

Finally, the results implicitly suggest an alphabetic categorization of the motor programs for the pronunciation of words. The first part of a word would activate the motor program for its pronunciation only if those programs were stored alphabetically. This notion is consistent with earlier speculations made on the basis of experiments on the tip-of-the-tongue phenomenon (Brown \& McNeil, 1966). In that study, subjects, when searching for a word to match a given definition, knew the first letter of the word $51 \%$ of the time. As in the present experiment, the first letters of a word appeared to be essential in the retrieval of verbal material.

\section{REFERENCES}

Brown, R., \& MCNeIL, D. The "tip-of-the-tongue" phenomena. Journal of Verbal Learning and Verbal Behavior, 1966, 5, 325-337.

ERIKSEN, B. ., \& ERIKSEN, C. W. The importance of being first: A tachistoscopic study of the contribution of each letter to the recognition of four-letter words. Perception \& Psychophysics, $1974,15,66-72$.

Reicher, G. M. Perceptual recognition as a function of meaningfulness of stimulus material. Journal of Experimental Psychology, 1969, 81, 275-280.

Smith, F. Psycholinguistics and reading. Toronto: Holt, rinehard, and Winston, 1973.

Thompson, M. C., \& Massaro, D. W. Visual information and redundancy in reading. Journal of Experimental Psychology, 1973, 98, 49-54.

W ARREN, R. E. Association, directionality and stimulus encoding. Journal of Experimental Psychology, 1974, 102, 15i-158.

Wherler, D. D. Processes in word recognition. Cognitive Psychology, 1970. 1. 59-85.

(Received for publication March 31, 1975; accepted May 21, 1975.) 